\title{
Participant reflexivity in organizational research design
}

\begin{abstract}
Despite the considerable interest in researcher reflexivity within the organizational literature, little attention has been paid to participant reflexivity, here defined as the reflexive considerations of research participants that are stimulated by their involvement in research. Our argument is that engagement in the research process is a context where such reflexive thinking is likely to happen and that through certain methodological approaches, participant's reflexive thinking becomes more conscious and therefore potentially accessible to the researcher. In identifying the participant reflexivity that emerged as part of a photo-elicitation study of work-life balance and conflict, we outline the kinds of reflexive dialogue that participants' reported as being stimulated by involvement in the research and explore the link between emotion and reflexive practice. Hence our paper contributes to our understanding of qualitative research and reflexivity first by highlighting empirically the kinds of internal dialogue reported when participants engage in self-reflexivity as part of the research process; second by outlining how we can access participant reflexivity methodologically including through emotions; and third by explicating the value for researchers in accessing participant reflexivity.
\end{abstract}

Keywords: Reflexivity; participant reflexivity; photo-elicitation; qualitative; work-life balance; daily / episodic research. 


\section{Participant reflexivity in organizational research design}

\section{Introduction}

Since the Hawthorne effect was first identified, organizational researchers have known that taking part in research can impact upon participant behaviours beyond the results initially predicted. Indeed, just being part of a research project can encourage participants to think and reflect upon the issue under consideration with a variety of potentially unexplored consequences. Despite this recognition however, beyond a recent consideration of the use of video (Whiting, Symon, Roby and Chamakiotis, 2016), there is little exploration or understanding within the methodological literature about the impact that research participation has on the reflexive thinking of the researched. This is surprising given the increased fascination with researcher reflexivity, where the researcher is encouraged to explore their own role in research ranging from their methodological preferences to their impact upon knowledge production (Johnson and Duberley, 2003; Cunliffe, 2003, 2004). Indeed within the organization studies literature, the focus has very much privileged the reflexivity of the researcher over that of the researched (Weick, 2002; Hibbert and Cunliffe, 2015). In this paper, we turn the focus away from the researcher to consider participant reflexivity. By participant reflexivity we mean the thinking that participants do that is stimulated by their involvement in a particular research project and the potential consequences of that thinking.

Why is this issue important for organizational researchers? Social theory highlights that people are naturally reflexive beings. As Archer (2007:2) suggests "At its most basic, reflexivity rests on the fact that all normal people talk to themselves within their own heads usually silently and usually from an early age". Indeed reflexivity is seen as one of the ways in which we make our way through life. Therefore, given this and the acknowledgement that 
involvement in a research project can impact upon individuals (Whiting et al., 2018), we would expect that our research participants would be reflexive about their involvement in our research. Access to this reflexive thinking, or to reports of the internal conversations that the researched engage in as part of the research process, could bring potential insights for organizational researchers. Specifically, an understanding of participant reflexivity could lead to a richer and more detailed framework from which to make sense of and analyse the data we collect. Hence our intention here is to bring our research participants into consideration as reflexive beings and to explicate how this reflexivity can be explored methodologically.

In what follows, we explore the ways in which participant reflexivity emerged through our use of photo-elicitation methods when we set out to study the ways in which research participants' experienced daily work-life balance or conflict. Our interest in this topic emerged in a serendipitous way. When asking our participants how they had found using the photo methodology (a method none of the authors had trialled before), we found that it had led to many of them questioning their own presumptions and actions about their work-life balance in some detail. Some suggested they were planning actions to address the work-life challenges they had identified. We concluded that participation in the research had stimulated a form of reflexive practice that was worthy of further exploration and was of interest to organizational researchers more generally. If our participants were behaving in this way, it maybe that other participants in other research projects are also doing the same.

In exploring the nature and impact of participant reflexivity we begin by examining the literature on reflexivity as it relates to everybody rather than just researchers. We draw particular attention to the notion of self-reflexivity (Cunliffe, 2002) as an important form of internal dialogue and to the literatures that forge links between emotion and reflexive practice (e.g. Hibbert et al, 2017; Burkitt, 2012). After briefly outlining the research project and the methodology, we summarize the reflexivity that participants reported as being facilitated by 
involvement in our research. We then focus upon the characteristics of reported participant reflexivity; how it can be accessed and facilitated methodologically; and the added value of such access for organisational researchers. Hence our paper contributes to our understanding of qualitative research and reflexivity first by highlighting empirically the kinds of internal dialogue participants report engaging in as part of the research process; second by outlining how participant reflexivity can be accessed methodologically including through emotions; and third by explicating the value for researchers in accessing such reflexivity.

\section{Reflexivity}

The concept of reflexivity has a long history. Rooted in ancient philosophy, it has been operationalised in a wide range of different philosophical and disciplinary perspectives (Schippers, Den Hartog, Koopman and van Knippenberg, 2008; Cunliffe and Jun, 2005). For many authors reflexivity is a relatively normal process that we all engage in with a variety of purposes and outcomes. For example Archer (2007) sees reflexivity as an on-going internal conversation that individuals have with themselves; and Giddens (1990) highlights how it enables people to make continual changes in their lives in response to knowledge about social circumstances. Myers (2010) further characterises reflexivity as something that we develop as we grow: "A person is not born to reflexive practice; it is a cultural pattern for interpreting the world that one has to learn" (Myers, 2010: 21). This view is also visible in the debates surrounding reflexive modernity (Beck, Giddens and Lash, 1994). The argument is that as individuals become less attached to the old ties of kinship and structures there is a need for the intensification of individual reflexivity (Archer, 2007).

In terms of conceptualising how participant reflexivity works in practice, a key notion is that of the internal conversation or the inner dialogue an individual has with oneself about a particular issue. Archer (2007: 73) highlights the distinctive features of these internal 
conversations as being silent and private; they are personalised, unique, context dependent and that we talk to ourselves without misunderstanding. Indeed we can all relate to such descriptions of our inner voice, the conversations, discussions and even arguments that we have with ourselves privately. As Archer (2007:87) points out, we are all "little gods" of our own inner dialogues and as such we "dictate their agendas".

The assumption that reflexivity is part of normal everyday practice has led to a variety of research studies that have investigated the role of reflexivity from different perspectives. Studies for example have explored the relationship between reflexivity and social mobility (Archer, 2007), charitable donations (Sanghera, 2017), institutional work (Ruebottom and Auster, 2018); routines (Yamauchi and Hiramoto, 2016); transformational leadership and teams (Schippers et al, 2008) and responsible careers (Tams and Marshall, 2011). Importantly there is a growing interest in building reflexive practitioners in arenas as diverse as education, national security and national environmental policy (Myers, 2010).

There is also a burgeoning literature within organization studies which highlights the role and contribution of researcher reflexivity (Cunliffe, 2003; Weick, 2002; Johnson and Duberley, 2003; Hibbert, Sillince, Diefenbach and Cunliffe, 2014). This literature outlines the variety of benefits of reflexivity for researchers including: enabling us to think about our own thinking (Haynes, 2012), and in questioning our own taken-for-granted beliefs and those of others (Ripamonti, Galuppo, Gorli, Scaratti and Cunliffe, 2016). Reflexivity also supports the inclusion of the researcher (Hardy, Phillips and Clegg, 2001); helps "more imaginative, nuanced and richer interpretations" from our data (Cunliffe, 2011: 409); plus has an important role in convincing qualitative writing (Jonsen, Fendt and Point, 2018). Within these debates, some have argued the need for a more relational conception of reflexivity that moves away from a researcher-centric perspective (Hibbert et al 2014). In this case, attention is devoted towards encouraging researchers to be more reflexive in accounting for the 
participant's standpoint when analysing data (Riach, 2009) around co-research environments where "researchers and informants [are] working together as a team to co-produce knowledge" (Takhar and Chitakunye, 2012: 932). These perspectives emphasize that richer and more nuanced interpretations may be achieved by gaining an insight into the reflexivity of our participants, but this has yet to be explored in any empirical detail.

\section{Towards a reflexivity of the researched}

Given the increased interest in reflexivity, a key question becomes how we can both understand and access the reflexivity of research participants. In making sense of how participants may respond in a research situation, it is useful to consider Cunliffe's (2002) notion of self-reflexivity. Drawing on Shotter's (1993) work about practical theories, she highlights how in the dialogic learning process individuals construct practical theories; "ways of accounting for and shaping experiences from within the experience itself' (Cunliffe, 2002: 36). Cunliffe's (2002) account is located within a management learning context, yet we might expect that research participants may also connect with their own dialogical processes in a similar way when they are involved in research. Indeed in an analogous way to management learning, involvement in research creates opportunities in terms of time and space to think about a particular topic under investigation. Particularly significant to the research process is that reflexive dialogue is initiated through a process of reflexive interaction, (Cunliffe, 2002:49) which refers to the "instantaneous, unselfconscious, reacting in the moment dialogue characterizing an individual's experience... responsive to other participants and the otherness of our surroundings". Reflexive interaction is not self-conscious therefore, but rather borne out of "instinct, feeling or habit" (Cunliffe, 2002: 49). Burkitt (2012:466) indicates that "other people and voices, populate the reflexive dialogue or drama that participants envisage, that participants may imagine as the judgements in the minds of others, which shape the way participants are likely to respond". In this sense, as part of the research 
process, the researcher, as well as other imagined audiences, become the 'other people and voices' with which participants reflexively interact as they think about and attempt to understand how they relate to the topic under discussion.

\section{Reflexivity and emotions}

We would also expect that participant reflexivity will be very much entangled with emotions as previous literature suggests that reflexivity can either be prompted by or be a result of emotional experiences (Hibbert et al. 2017; Burkitt, 2012; Cunliffe, 2002). Cunliffe (2002) indicates the key role of emotion in triggering self-reflexivity as part of a dialogical process. She notes the difficulties associated with pre-determining such reflexivity, and makes suggestions for researcher's conversational styles around initiating and understanding the participant's expressed internal voice. These include emphasizing reflective dialogue and using storytelling. Burkitt (2012) argues that dialogic reflexivity is bound up in relations with others and since the relationships we have are usually immersed with emotion, reflexivity is an emotional process. Indeed he argues that "a whole range of emotions colour, enliven and animate those social relationships and are central to our reflexive thinking and choices" (Burkitt, 2012: 461).

Increasingly writers are recognizing the emotional aspects of the research process (Evans et al.; 2017; Roulet, Gill, Stenger and Gill, 2017; Hansen and Trank, 2016). Hibbert, Callagher, Siedlock, Windahl and Kim (2017) suggest potential directions available to those interested in exploring the connections between reflexivity and emotion. One is that as noted earlier, the researcher can pay attention to their own emotions in the research process leading to potential insights for the analytic process. 
Another is that emotions can be key pivot points for reflexive practices in that they open up different forms of understanding. The authors suggest that a key question here is how our awareness of our emotions informs our reflexive practice. We would anticipate that this is the case for both researchers and the researched. Hibbert et al., (2017) also note that there is some debate about whether emotion can be seen as a barrier to reflexive thought (Burkitt, 2012), however, in conducting research with participants, it could be that as the authors suggest, we are calling them to action or to see themselves as agents or authors of their organizational worlds, a call for action that can be both rationally understood and emotionally experienced (Hibbert et al., 2017: 4).

Hibbert et al.'s (2017) work centrally emphasizes that the call to change is either mobilized or constrained based on the combined effects of (sub) conscious emotional experiences and rational reflexive practices. It also importantly enables a recognition that although emotions can be important triggers or pivot points for reflexivity, the process of reflexivity does not necessarily lead to change. Therefore in investigating reflexivity as part of the research process we need to explore its implications not just for action, but also for the emotions (conscious or otherwise) that stimulate reflexivity or which are brought to the surface because of it. We would expect that these emotions are very much entangled with experiences of participant reflexivity. Just as existing literature highlights how awareness of researchers' emotional experiences and reflexive practices is an important part of the analytic process (Whiteman et al., 2009; Evans et al., 2017), we would argue that the same is true for our awareness of the emotions and reflexive practices of our participants.

\section{Accessing the reflexivity of the researched}

Various writers have considered how we may access the reflexive considerations of the researched. Caetano (2015) drawing from a sociological perspective argues that 
translating the theoretical principles about how we understand reflexivity as a series of methodological tools involves a number of practical challenges. These include the challenge of observation, how do we access an individual's private thoughts based on what we observe, especially as “each person's discourse is filtered by memory, experience, social circumstances and emotional states" (Caetano, 2015: 229). The research situation may also be unusual compared to how people usually communicate or think in that interviews may be a somewhat "extraordinary situation" which implies a break from how people usually talk (Caetano, 2015: 232; Alvesson, 2003).

Ruebottom and Auster (2018) connect with research from critical pedagogy and social movements that has identified how particular forms of communication such as story-telling or dialogue (Cunliffe, 2002) can be reflexive triggers as they enable participants to challenge the norms by which they live their lives. This challenge of taken-for-granted assumptions is seen as a key underlying premise of reflexivity. Islam (2015) introduces the notion of paraethnography where organisational members (the researched) take an active role in research and become involved in theory-building through offering insights from their own culture in a way that enhances collaboration between the researcher and the researched. Given that our research participants may contribute their reflexive views from a critically reflexive stance but are not in practice "ethnographers", the term "para-ethnography" effectively captures this position.

Other suggestions emerge from discussions of the impact of visual methods in facilitating participant reflexivity. For instance, Toraldo, Islam and Mangia (2016: 13) suggest that one of the ways that video analysis has been used in organizational research is as a "reflective artefact". They suggest that within this approach reflexivity is located within the exchanges between the participants and the researchers and can promote sensemaking where participants reflect upon what they are doing on the screen, a process that has been described 
as “zooming with" by Jarrett and Liu (2018). Whiting et al. (2018:18) highlight how within their participatory video project, the videocams technology enabled participants to edit and review their own data about their work-life balance, leading to some experimenting with ideas to improve their work-life balance.

These kinds of studies involve a process of going back to the researched after the initial research has taken place but the impact and purpose of this has rarely been explored within the methodological literature beyond some consideration of respondent validation (Cassell, 2015) and in longitudinal designs (Langley and Stensaker, 2012), neither of which focus upon participant reflexivity. One notable exception is the work of Gatrell (2009) who explored the long-term effects of qualitative interviews on respondents by returning to a set of interviewees after her initial study. Gatrell was interested in safeguarding and exploring whether the participants had been compromised by taking part in her research. She found that whereas some had found the process cathartic and felt it had enabled reflection, others struggled to remember the experience.

In summary, we have learned a number of things from the literature review that are pertinent to our understanding of participant reflexivity. We know that it is an everyday human practice characterised by internal dialogue (Archer, 2007) and that internal dialogue involves constructing practical theories and thinking critically about our experiences (Cunliffe, 2002), but also that being part of the research process is likely to constitute an "extraordinary situation" (Caetano, 2015: 232). We also know that the emotional aspects of these experiences can be key, pivot points for reflexivity and can lead to action planning (Hibbert et al., 2017; Burkitt, 2012). However, what is missing from our understanding is an awareness of the specific kinds of internal dialogue generated when participants engage in such reflexivity as part of the research process and an appreciation of how we can access this participant reflexivity methodologically. There are some suggestions as to the kind of 
environments more broadly which may encourage individuals to become more reflexively aware (e.g. Cunliffe, 2002) but these discussions are not focused on research participants specifically. However, we would argue that there may be some unique elements of the research encounter that are worthy of investigation. A number of authors have noted that the research process is unusual as a form of social interaction (e.g. Caetano, 2013; Alvesson, 2003) because individual participants are disclosing often very personal information to a stranger in a way that they may not ordinarily do so. We know that these internal dialogues or processes of self-reflexivity are usually private, however it could be that access to participant's accounts of them by researchers could have considerable benefit both for the quality of the data collected and the frameworks that inform our subsequent data analysis. We also have the opportunity to learn more about both the links between reflexivity and emotions and our topic of investigation by accessing our participant's reflexive thoughts. Therefore, while we have noted that reflexivity is part of individual's everyday lives, we would contend that the research process creates an environment conducive to more concentrated, detailed and focused reflexivity that rarely exists in other daily circumstances.

In the light of the above, here we focus upon three research questions:

- What kinds of internal dialogue are reported as being generated when participants engage in self-reflexivity as part of the research process?

- How can participant reflexivity be facilitated and accessed methodologically?

- What is the added value for researchers in accessing participant reflexivity?

We now outline the research study that formed the basis of our investigations.

\section{Study description}

The aim of the research was to gain a deeper understanding of the holistic nature of work-life relationships through a focus upon daily practices as part of a longitudinal, episodic 
research design using multiple qualitative methods including photo-elicitation. Given that the work-life literature has been critiqued for focusing upon restrictive understandings of the concept (Özbiglin, Beauregard, Tatli \& Bell, 2011), we were keen to grasp how this is understood and negotiated in daily practice. The sample was recruited through a snowball approach consisting of 37 participants, 30 women and 7 men. Demographic details of the participants are presented in Table One where pseudonyms are also provided.

Insert Table One about here

The instructions given to participants regarding the photographic elements of the research design are based primarily on similar instructions offered by Vince and Warren (2012: 295) who outline the notion of "responsible photography". Participants were asked to send six photographs to the researchers that characterised their experiences of work-life balance or conflict. In response, participants captured a diverse set of images including photographs associated with work such as desks, lunches, and aspects of the work environment; those that captured the transition between work and home; and photographs that captured 'life' or home, for example of their children, leisure activities and household chores.

Interviews were arranged with participants on submission of their photographs. There are a number of different approaches that can be taken by qualitative interviewers. Here our approach is located within what Alvesson (2003) labelled as romanticism where the intention is to establish trust and rapport with the interviewee so that we can effectively explore their social reality and sensemaking around the concept of work-life balance. As Alvesson (2003: 16) says, these interviews typically seek to accomplish "deeper, fuller conceptualizations of those aspects of our subjects' lives we are most interested in understanding" (Miller \& Glassner, 1997: 103). Alvesson points out the implications of using a romantic metaphor in understanding the interview process in this way in that we assume that the interviewee is in a 
highly ambiguous situation where intensive sensemaking is required. We would suggest that such intensive sensemaking can involve the participant in self-reflexivity and that this can be facilitated by the types of question that the researcher asks.

Our interviews started with the interviewer asking the interviewee about each of their photographs in turn. Interviewees were asked to talk about the photograph, what was in it, why they had taken it, how it made them feel, and what the photograph captured about the relationship between their work and non-work roles. Once each of the photographs had been discussed, the interview continued with further probing in-depth and detailed information about their experiences of work-life balance and conflict. At the end of the interview, participants were asked a series of questions about these and the impact more generally that being involved in the research had on their understanding of their own work-life balance. It was this kind of response that first alerted us to the concept of participant reflexivity. When the research team reflected upon the data provided and the interview process more generally we realised that as part of the interview process we had created safe spaces for reflexivity. For example, through letting participants choose their own location for the interview; the use of open questions and participant-led discussion when asking them to explain their photographs; and through seeking clarification during the interview questioning by using reflection. However, it wasn't until after the first stage of the analysis that we sought to delve more into this aspect of the data.

The responses of participants were analysed using thematic analysis as prescribed by King and Brookes (2016). Here we were not analysing the content of the photographs, but rather any part of the interview transcripts where participants discussed their experiences of taking photographs and the impact this had for how they were making sense of their work-life balance. King and Brookes (2016: 6) highlight how "Template analysis does not have a 
single fixed position in the induction-deduction balance; this will vary according to the kind of methodological approach within which it is being used". Here an initial template of themes was established by the first author inductively from the transcripts. Initially the themes identified were focused very much upon the method itself, for example how they had approached the photographic task. However, there was one theme in the template, initially labelled as 'reflections', that in discussing the analysis as a research team we all found to contain the most interesting data. This was where participants were reporting the outcomes of their reflexive thinking. Hence we then decided to re-analyse the data with the issue of how we could understand the reflexive thinking of participants in mind. Through repeatedly reading and re-reading the transcripts, it became apparent that as we had initially suspected, there was a broader narrative within the data about how reflexive thinking was enabled by our research process. Although our initial analysis of their responses to the photographic method was interesting, it did not do justice to the self-reflexivity that was at work. This reanalysis of the data was initially conducted by the first author. At this time, data excerpts initially classified as advantages of the methods - for example it enabled a participant to rethink their taken-for -granted assumptions about their work life balance - were on further interpretation deemed more significant than merely a methodological advantage.

In the second iteration of the template we sought to code the data according to different aspects of participant reflexivity identified. At this stage the first author identified eight different aspects of the reflexive process which were represented by eight themes in the template. After sharing and discussing the template with the research team, some themes were collapsed (for example the themes of 'performing the self' and 'work-life stories' were integrated into a new theme of 'constructing self-narratives'). This led to the third formulation of the template comprised of four themes which categorised how participant reflexivity could be understood. Within this template there were four themes. These were 
constructing self-narratives; critiquing taken-for-granted assumptions; dialogues connecting with emotions; and change dialogues. Given the iterative process between the first author conducting the analysis and reflexive discussions with the research team, we were confident that we had met the conditions for an internally reflexive audit trail (Johnson et al, 2006). We now use the outcomes of our analysis to address each of the research questions in turn.

\section{What kinds of internal dialogue do participants report when engaging in self-}

\section{reflexivity?}

Our first research question asks about how we can characterise the different types of reflexive dialogue that participants reported engaging with. These different types of dialogue are summarised in Table Two.

\section{Insert Table Two about here}

The first type of dialogue identified is constructing a self-narrative. Participants engaged in internal reflexive conversations in regard to the photographs they chose to take and send to the research team. As part of the decision-making process about which photographs to submit participants considered how their photographs would be interpreted by the researcher and the impression of themselves that the photographs would convey. In choosing their photographs they were creating their own narrative of their work-life balance. For example Chloe suggested that she agonised over whether to take a photograph of her desk:

"I could have done, I don't know whether to take my desk, but I don't know if that would be such a good story.

I: Does it represent your work-life balance or work-life conflict or anything in any way, your desk?

R: Just that it's where I sit all day for like a big part. Just to illustrate my life... But I thought I'd choose some things to illustrate that my life isn't all about work". (Chloe) 
Here Chloe's reported internal conversation was about whether she should present 'a good story' about her work-life situation or rather merely document something she saw as a key part of it. Chloe's apprehension around choosing a good story could stem from her desire to please, to conform to what she thinks the researcher wants. As noted earlier (Burkitt, 2012) her internal voice cannot be separated from how she imagines others will react to it. So Chloe tries to find a good story, perhaps being mindful of being judged by the researchers.

In reflecting upon and sharing their work-life stories in some cases participants had an idealised view of an alternative form of work-life balance which they would have preferred to portray, rather than the one indicated to the researcher through their chosen set of photographs. For example, Anthea discussed how she would have liked a photo of the family walking in the park:

"I was thinking about work-life balance and I was thinking about what I do and it just came to me. What I didn't have, which is the downside, is that there wasn't the walk in the park, which I would have loved there to have been..." (Anthea)

Having access to Anthea's reported internal conversation about what she thinks is missing from her research data enables us to see her reflexive thinking about her work-life balance. This is informed by popularized notions that work-life balance is something that individuals should strive to achieve. Here we can see the impact of societal norms and discourses on individuals' internal conversations and personal narrative construction.

The second type of reflexive dialogue involved challenging the taken-for-granted nature of their work-life balance. For example:

"I think it really makes you think about your life as a whole. I'd not really thought about it in those terms before; you don't really perhaps. You just sort of bowl along through your life and then... Thinking about it's really, sort of, brought up various aspects. I think, "oh yeah, I suppose, you know, why am I selling up and why did I do it like that, why did I do it?" I don't really know, I just did, you know?” (Pamela) 
The self-awareness generated by the reflexive process meant that participants had the opportunity to understand and critique their own assumptions and feelings with regards to what represented work-life balance for them personally, and the different elements of their life that enabled them to achieve such balance. It also enabled them to question assumptions and routines that they had previously taken for granted:

"It made me realise my own work-life balance... I realised having a glass of wine, that that is also part of work-life balance. Buying something for the kids, that is also part of work-life balance, you are able to buy expensive toys for them because you are working, and you are able to afford it. So I had never thought of these things from that angle but after you asked me to do it, it made me think and I quite liked it actually because it gives you a different angle to think of your work and life" (Roxanne).

The third form of internal dialogue reported was emotional. For example:

"It makes me feel quite raw in a way, because obviously I am telling you things and I am talking to you about some of my failings and frustrations, some of the things that make me feel upset. Do I really want to be reminded of where my failures are so explicitly? Yeah, it's difficult and it makes me feel quite inadequate... These are the things that both upset me and frustrate me... Upsetting, and enlightening I suppose". (Rosalind)

Earlier we noted that Hibbert et al. (2017) identify how emotions can be key pivot points for reflexive practices in that they open up different forms of understanding. As the examples in Table Two highlight, the emotions aroused when thinking about the topic can trigger self-reflexivity and a re-evaluation of work-life balance and personal situation. The reflexive work participants did around their work-life balance was entwined with, and often instigated by, a range of different emotions including positive emotions such as joy, pride and happiness and negative emotions such as anger or guilt highlighting for us the emotional complexity surrounding daily work-life experience. Participants themselves might not have been aware of these connections until they engaged in their reflexive thinking as part of the research process, yet as Hibbert et al. (2017) highlight, the emotions those connections 
generated can be seen as pivotal in facilitating reflexive thinking. Cunliffe (2002) notes how previously unknown or unrealized emotions can connect to experiences that are brought into consciousness through reflexivity, rather than remaining below the surface and therefore unexamined. As the examples in Table Two highlight, the surfacing of these positive and negative emotions during the research process meant that participants had to engage with some of the more problematic aspects of their work-life situation. They had clearly had internal conversations about these which they then chose to share with the researcher.

The fourth form of reflexive dialogue is related to action. As noted in the literature review, some authors (e.g.Giddens, 1990) have highlighted how reflexive processes enable individuals to make small and continual changes in their lives. Perhaps it is not a surprise therefore that some of our participants suggested that the opportunity for reflexive critique led to them planning or activating behavioural changes. This link between reflexivity and action demonstrates how as Hibbert et al., (2017) suggest, reflexive practice can lead to a call for action. In line with their suggestion, it is the combination of the emotional experiences and reflexive practices that will impact upon whether a call to action is either mobilized or constrained. Within Table Two we see some different responses to calls for action. Whereas for Micha her response is to resign herself to the position that things are unlikely to change, for both Naomi and Roisin, their reflexive thinking has mobilized them to act.

In summary, in accessing participant reflexivity we see that the internal conversations our participants reported share the characteristics of those outlined by Archer (2007). They are personally unique and context dependent, but also relational in terms of participants' evident responsiveness to the imagined evaluations of others when constructing their own stories (Burkitt, 2012). Adams (2006) notes that different contexts offer various opportunities to facilitate reflexive thinking. Our argument here is that engagement in the research process is a context where such reflexive thinking is likely to be brought to the fore. As demonstrated 
by our participants, in order to answer the questions put to them by the research team, they thought carefully about the appropriate data to present and what that data might say about them. This thinking required internal conversations about their own work-life balance which led to the challenging of their taken-for-granted assumptions which they had become more conscious of because of the emotions generated around their reflexive thinking.

\section{How can participant reflexivity be facilitated and accessed methodologically?}

Based on our analysis we would suggest that we need an appropriate methodological approach to enable us both to facilitate and access these reported internal conversations. From our study we identify four key methodological characteristics that enable participant reflexivity to be facilitated and accessed. These are summarised in Table Three.

\section{Insert Table Three about here}

The first characteristic that supports the facilitation of participant reflexivity is including the opportunity for reflexive space as part of the methodology. Cunliffe's notion of self-reflexivity focuses upon the need for individuals to be able to access their own dialogic processes so during the research respondents need the time to actually think about the topic of interest. In terms of research design a longitudinal element is helpful here. There needs to be a period of time between the researched thinking about their data, and when the data is communicated to the researcher. In this case there was a period of time between the taking of the photographs and the sharing of them with the researcher which encouraged self-narratives to emerge. Other researchers who have accessed participant reflexivity have also included this longitudinal element, for example Caetano (2015) highlights how biographical interviews enable a prolonged period of contact with the interviewee and Whiting et al. (2018) address this through participants editing their own video data. This longitudinal element has also been 
included when researchers have returned to participants after the research is complete, for example Gatrell's work on safeguarding.

The second related characteristic is the anticipation that participants will be sharing their data with the researcher. In this case participants had to do something without the researcher present (take a photograph) which they knew would be discussed with the researcher at a later stage. The anticipation and preparation involved beforehand facilitated reflexive thinking via encouraging the construction of self-narratives and beginning to question elements that were previously taken for granted. As noted earlier, "other people and voices" populate the reflexive interactions of individuals (Burkitt 2002: 466). Our internal voices are influenced by how we anticipate others will respond to them, indeed sometimes others are present in the private dialogues we have within our heads. Although here we used photographs, other methodological approaches which could facilitate this anticipation could be participant diaries (Radcliffe, 2013), filling in questionnaires or projective techniques such as the Twenty Statements Test (Rees and Nicolson, 2004) and then sharing them with the researcher, or even presenting participants with the interview questions in advance for them to consider pre-interview.

The third characteristic of a research design to encourage participant reflexivity is a participant-led element of the research process (Riach, 2009). In this case participants could take photographs of whatever they wanted in relation to their experiences of work-life balance and conflict. Not only did this encourage the construction of participant selfnarratives therefore stimulating reflexivity, as they decided what to take, and not to take photographs of, but it also enabled them to feel more in control of the interview process itself. As the interview started with a discussion of their photographs, they were very much in control of setting the content of the conversation, increasing feelings of participant safety and personal power. These are characteristics that facilitate a positive, trusting interview 
environment, one which enhances researcher-participant rapport (Alvesson, 2003) and thus facilitates greater likelihood of revealing private, personal thoughts and making the subconscious conscious. The advantages of a participant-led element of the research process have been recognised in the literature on photo-elicitation (e.g. Vince and Warren, 2012; Ray and Smith, 2012), but can also be associated with other methods, for example diaries (Radcliffe, 2013) or creating a video (Toraldo et al., 2016; Whiting et al., 2018). An additional advantage of such participant control is that this kind of participant-led research supports a comfortable environment for reflexivity, which the researcher can then access.

The fourth methodological characteristic focuses particularly on how we might access participant reflexivity through creating the opportunity for relational dialogue between the researcher and the participant. In this case a follow-up interview enabled the research team to directly ask questions about the internal conversations that had taken place. The sharing of these internal conversations with the researcher also means that reflexivity becomes more relational. According to Burkitt (2012) it is the relational aspects of reflexivity that are entangled with different emotions and it is only when we articulate how we feel to others that emotions start to become more conscious and specific. Hence it is important here that through the data collection process the researcher pays attention to the emotions that are being generated and reported so that these can be explored further. In Cunliffe's (2003) terms, this can be seen as the requisite "conversational style" for both facilitating and accessing the participant's internal voice. We would also suggest that the researcher needs to demonstrate empathic and responsive behaviours during the interview process where the participant is sharing their reflexive thinking, for example through sensitive follow-up questioning. Overall, it is important that the research environment is a space where relational dialogue can thrive and the participant is comfortable to disclose. 
To summarise, the characteristics of research design we have identified here as facilitating and enabling access to participant reflexivity are an opportunity for reflexive space which may occur via a longitudinal design where participants have the chance to think about the particular topic or issue; anticipation that the participant is going to share their data with the researcher; participant control to permit participants to choose what is focused upon therefore encouraging reflexivity to enable this choice; and relational dialogue in that the participant and researcher have the opportunity to discuss the participant's internal conversations in a safe and open environment.

For the qualitative organizational researcher who wishes to capture this kind of data, the suggestion is that they try to incorporate all these characteristics within their research design. Within an interview or focus group situation for example, anticipation, reflexive space and control could be afforded by providing interviewees with a list of questions for reflection before an interview, and then asking them to come to the interview prepared to talk about them. Within the interview there then needs to be an opportunity for relational dialogue to discuss these reported internal conversations, encouraging participants to share their anticipatory thoughts and choices before the interview and exploring these in as much detail as possible. Another alternative would be that after an interview or focus group, participants could be approached again about their views after a period of time, through a follow-up telephone interview for example. The important point here to facilitate participant reflexivity would be that the participants know that a follow-up is happening. This would provide the anticipation, reflexive space, opportunity for reflexive dialogue, control and longitudinal element as required. Given Gatrell's (2009) findings that some interviewees had forgotten their involvement in her research after six years, a short time window is preferable. 


\section{What is the added value for researchers in accessing participant reflexivity?}

Our final question tackles the added value of accessing participant reflexivity for the researcher. In Table 4 the added value of participant reflexivity is summarised.

\section{Insert Table 4 about here}

As noted in Table 4, a focus on participant reflexivity adds value in that it both promotes and positions our participants as reflexive individuals. The data excerpts in the first row in Table 4 all draw attention to participant's understandings of their reflexive thinking. In promoting this conception we are recognising how reflexivity is an everyday process that develops over time (Archer, 2007; Myers, 2010) and that our research participants will engage in reflexivity as part of the research process. In positioning our participants as reflexive individuals it then makes sense to seek ways in which we can access their reflexive dialogue to add value to our research. The added value here is similar to Islam's (2015) notion of para-ethnography in that our participants are contributing their views from a critically reflexive stance in offering insights from their own culture and experiences. Hence this will serve to both enhance the collaboration between the researcher and the researched and to develop theoretical insights. Given the increasing interest in researcher reflexivity in the qualitative research field (Cunliffe, 2002; Johnson and Duberley, 2003) it seems only right that we equally treat our participants as reflexive beings and strive to move away from a researcher-centric perspective (Hibbert et al., 2014).

A second advantage is that access to individual sensemaking enables a more nuanced interpretation of our data for example an in-depth analysis from participants about their rationale for why they do specific things or why particular things are important to them. A legitimate question here could be how is this different from the kind of data that might ordinarily be produced in a qualitative interview for example? Our suggestion is that where 
participant reflexivity is enabled there is an added value in that the data has not just been generated in situ. Rather, the participant has already started the analysis process through their reflexive process and the internal dialogues that have taken place. This means that they can offer more in-depth explanations of why they do things in the way they do, and the decisions and choices that they have made, allowing us to move beyond initial surface level responses. For example, from the data excerpts presented in the second row in Table 4, we can see additional insights into their sensemaking about the research data that they have provided.

The third advantage we identify is the potential for a more nuanced understanding of our research topic. For example, in this case our access to participant's reports of their internal conversations enables us to see the normative pressures individuals face in terms of both seeking and presenting a convincing narrative about their work-life balance, such as Anthea's example about wanting to include a walk in the park. Here participant reflexivity enables us to move beyond descriptions and responses representative of normative expectations, and instead supports in-depth explorations permitting a more nuanced understanding of the underlying issues at play. As noted earlier, the literature on work-life balance has been critiqued for the restrictive understandings of the term 'work-life' and the lack of attention paid to different interpretations of the term (Özbiglin et al, 2011). Accessing the reflexive dialogue of participants has demonstrated to us how terms such as work-life balance can be problematized, not just for researchers, but also for research participants.

We would anticipate that a focus on participant reflexivity would also be useful in other fields of organizational research where definitions and meanings are similarly contested. Examples include identity research where a key challenge is understanding the processes and influence on identity construction (e.g. Brown, 2018). For example, explorations of identity work (e.g. Beech, 2008) benefit from participant's accounts of the internal dialogues they have in regard to creating a coherent sense of identity in a given 
organisational context. Another field is the extensive work on leadership where we would have the opportunity to access leader's reflexive thinking about a range of issues, for example decision-making, change and strategy (e.g. Alvesson, Blom and Svengingsson, 2017). Given the links between reflexivity and emotions we would also expect that the field of emotions and organisation could benefit from a reflexive understanding. Examples include studies of emotional labour where organisational members are not necessarily behaving authentically (Hochschild, 1983) and emotional coping in challenging circumstances, for example dirty work (Grandy, Mavin and Simpson, 2014). Here we would be able to access the reflexive dialogues that individuals draw upon when seeking to develop resilience in the workplace.

The fourth area of added value is offered through the way that participant reflexivity enables the surfacing of emotions and an exploration of the links between emotions, reflexivity and action. Whereas previous research has noted debates around whether emotions may actually be a barrier to reflexive thought (Burkitt, 2012), our research would suggest, at least within the context of the research process, that emotions acted as a reflexive enabler, triggering critical questioning around current practices and understandings. As the example of Alexi in Table 4 highlights, she becomes more conscious of the emotions she is experiencing leading to her questioning particular work-life experiences. The same happens for Hilary who mentions how she experienced emotional triggers when uploading her photographs. This access to her reflexive sensemaking and the role of emotions within it offers some evidence for the role of emotions as reflexive pivot points (Hibbert et al., 2017). Participants begin to think reflexively as emotions come to the fore. As noted earlier there is a variety of research that notes the emotional aspects of the research process from the viewpoint of the organizational researcher (Evans et al., 2017; Whiteman et al., 2009), but here the focus upon the emotions of the researched enables us to identify issues and events that are particularly pertinent to our participants, that are entangled within participant 
reflexivity processes. As Hibbert et al. (2017) note, and as we have also identified in our own participants, this may signify a call to change that can lead to participants changing their behaviours, or at least re-evaluating what they are currently doing. Not only does this signal an issue or event worthy of further exploration, but we would argue that the researcher also has some level of responsibility here to permit participants to explore and develop their reflexivity and emotions at such pivot points in a safe space (Hibbert and Cunliffe, 2015). Given that the phenomenon of emotional reflexivity is currently under-explored (Holmes, 2015) we would highlight the importance of researchers paying attention to this during the research process. Here emotions can provide a window into participant reflexivity and enable more in-depth insight into participant's issues around the topic of study.

Finally, we would argue that an added value of participant reflexivity is in enabling the researcher's own reflexive processes. The standard qualitative research process involves the researcher creating the research design and methods, collecting and analysing the data and then their reflexive thinking impacts upon both knowledge creation and the outputs from the research (Johnson and Duberley, 2003). However, the inclusion of participant reflexivity in the research design offers an added dimension in that participants' reflexive thinking also contributes to the data collection and analysis. It poses the opportunity for additional insights that the researcher can feed into their own reflexive processes which in turn leads to more nuanced knowledge creation and outputs. It also offers a way of facilitating reflexivity as a more relational process as called for by writers in this field (e.g. Hibbert et al., 2014). Thinking reflexively as researchers, this process has underpinned the narrative for this paper, in that our unexpected access to our participant's reports of their the inner reflexive dialogues enabled us to critique reflexively the impact of our research design which in turn led to more informed research findings about our topic of study.

\section{Conclusions}


In conclusion, qualitative researchers have long been aware that offering the opportunities for people to talk about their work and organizational experiences will potentially have an impact on them but the participant's experiences or responses to this engagement in research have rarely been systematically investigated. Here we have contributed to the literature on reflexivity by highlighting the kinds of internal dialogues reported by participants engaging in self-reflexivity triggered by the research process. We have also demonstrated empirically how emotions can be reflexive pivot points (Hibbert et al., 2017) and their links to possible action. We have additionally offered some practical, methodological suggestions of ways in which other qualitative organisational researchers can access these important conversations. Finally, we have considered the added value for researchers in accessing participant reflexivity. In characterizing the nature of participant reflexivity and demonstrating how it is accessed, our methodological contribution here has been to draw attention to a phenomenon rarely explored or discussed within the organizational research methodology literature. We have argued that accessing participant reflexivity can have benefits for organizational researchers not least leading to a situation where both participant and researcher reflexive thinking can be incorporated in to a research design. Apart from a more nuanced and rich understanding of our data, in neglecting to consider something that is recognised as an everyday human process (Archer, 2007) we are missing out a crucial component of the research experience.

Whilst there is clear value for researchers in accessing participant reflexivity, there are some related ethical issues that we should be aware of. In facilitating the critique of important aspects of their lives, participant reflexivity may in turn lead to some emotional discomfort for participants. Hibbert and Cunliffe (2015) suggest that the learning process that accompanies reflexivity needs to move beyond the level of disturbance and doubt to create new forms of understanding. Therefore, rather than leaving our participants without the time 
or space to continue the reflexivity process that our research may potentially instigate, it seems important that we provide them with the opportunity to develop that new understanding in a safe and confidential environment (Hibbert and Cunliffe, 2015). For example, previous research on participation in qualitative research suggests that individuals often report their involvement as having therapeutic effects, providing an opportunity for them to be listened to by a person who genuinely wants to understand their stories (e.g. Miller and Boulton, 2007). Additionally, we would suggest that researchers, research supervisors and ethics committees should work to ensure that researchers are fully aware of issues surrounding participant reflexivity and that participant consent documents should also ensure that participants themselves are made explicitly aware of this, prior to providing their consent to take part.

Our discussion also raises a number of issues for further investigation. Future studies could focus upon understanding what different kinds of internal dialogue are facilitated by participant's engagement with different aspects of the research process and how different methodological designs might enable researchers to access this. For example, do visual methods facilitate greater levels of reflexivity because participants are better able to connect with emotions as images tend to trigger an emotional response (Stiles, 2012; Cassell, Malik and Radcliffe, 2017)? Furthermore, if emotions are central to the process of reflexivity because of connections to internal voice and relational dialogue (Burkitt, 2012), how does this relationship work in the context of other data collection methods? Going back to our participants (for example Gatrell, 2009), could also provide researchers with an indication of the extent to which participant reflexivity initiated during the initial data collection facilitated positive effects or resulted in subsequent positive action. Here there would be the opportunity to explore the post-reflexive choice highlighted by Adams (2006) and Hibbert et al. (2017). There is also the question of whether different types of groups, for example men and women, 
blue-collar and white-collar workers, or those of different ages, may be more likely to express their reflexive thoughts than others in the context of the research process. Future research could also explore whether different research designs may work to encourage reflexivity to differing degrees for different groups, as well as why this might be the case.

Finally, we would contend that in putting the focus on seeking to understand ourselves more as researchers and the choices we make, we are neglecting the contribution of those we are seeking to research. Given the opportunities that participant reflexivity offers to qualitative organizational researchers, we would hope to stimulate further discussion about this issue within the organizational research methods domain. 


\section{References}

Adams, M. 2006. Hybridizing Habitus and Reflexivity:: Towards an Understanding of Contemporary Identity? Sociology, 40 (3): 511-528.

Alvesson, M. 2003. Beyond neopositivists, romantics, and localists: a reflexive approach to interviews in organizational research. Academy of Management Review 28(1): 13-33.

Alvesson,M., Blom, M. and Svengingsson, S. 2017. Reflexive leadership: organising in an imperfect world. Sage publications.

Archer, M.S. 2007. Making our way through the world: human reflexivity and social mobility. Cambridge: Cambridge University Press.

Beck, U. Giddens, A. \& Lash, S.1994. Reflexive modernization: Politics, tradition and aesthetics in the modern social order. CA: Stanford University Press.

Beech, N. 2008. On the nature of dialogical identity work. Organization, 15(1): 51-74.

Brown, A.D. 2018. Identities in Organization Studies. Organization Studies, Online early, https://doi.org/10.1177/0170840618765014

Burkitt, I. 2012. Emotional Reflexivity: Feeling, Emotion and Imagination in Reflexive Dialogues. Sociology, 46(3): 458-472.

Caetano, A. 2015. Personal reflexivity and biography: methodological challenges and strategies, International Journal of Social Research Methodology, 18(2): 227-242.

Cassell, C. M. 2015. Interviewing for Business and Management students. Sage Publications.

Cassell, C.M., Malik, F. and Radcliffe, L. 2016. Using photo-elicitation to understand the complexities of work-life balance'. In K. Townsend, R. Loundon and D. Lewin (Eds.) Handbook of Qualitative Research Methods on HRM Cheltenham: Edward Elgar. 
Cunliffe, A.L. 2002. Reflexive Dialogical Practice in Management Learning. Management Learning, 33(1), 35-61

Cunliffe, A. L. 2003. Reflexive inquiry in organization research: Questions and possibilities. Human Relations, 56: 983-1003.

Cunliffe, A.L. 2004. On becoming a critically reflexive practitioner. Journal of Management Education, 28(4): 407-426.

Cunliffe, A. L. 2011. Crafting qualitative research: Morgan and Smircich 30 years on. Organizational Research Methods, 14: 647-673.

Cunliffe, A. L., \& Jun, J. S. 2005. The Need for Reflexivity in Public Administration. Administration \& Society, 37(2), 225-242.

Evans, E., McCarthy, J.R., Bowlby, S. and Wouango, J. and Kébé, F. 2017. Producing emotionally sensed knowledge? Reflexivity and emotions in researching responses to death. International Journal of Social Research Methodology,20 (6): 585-598.

Gatrell, C. 2009. Safeguarding subjects? A reflexive appraisal of researcher accountability in qualitative interviews", Qualitative Research in Organizations and Management: An International Journal, 4(2): 110-122.

Giddens, A. 1990. The consequences of modernity. Stanford: Stanford University Press.

Grandy, Mavin, S. and Simpson, R. 2014. Doing dirty research using qualitative methodologies: lessons from stigmatized occupations. Qualitative Research in Organizations and Management: An International Journal, 9(3)

Hansen, H. and Trank, C. Q. 2016. This is going to hurt: compassionate research methods. Organizational Research Methods 19(3): 352-375. 
Hardy, C. Phillips, N. \& Clegg, S. 2001. Reflexivity in Organization and Management Theory: A Study of the Production of the Research 'Subject'. Human Relations, 54(5):531-560.

Haynes, K. 2012. Reflexivity. In C.M. Cassell and G. Symon Qualitative methods in organizational research: core methods and current challenges. London: Sage.

Hibbert, P., \& Cunliffe, A. (2015). Responsible management: Engaging moral reflexive practice through threshold concepts. Journal of Business Ethics, 127(1), 177-188.

Hibbert, P., Sillince, J., Diefenbach, T. \& Cunliffe. A.L. 2014. Relationally reflexive practice: A generative approach to theory development in qualitative research. Organizational Research Methods, 17: 278-298.

Hibbert, P. Callagher, L., Siedlok, F., Windhal, C. and Kim, H-S. 2017. (Engaging or Avoiding) Responsibility through Reflexive Practices. Journal of Management Inquiry, 1-17.

Hochschild, A. 1983. The managed heart. CA: University of California Press.

Holmes, M. 2015. Researching emotional reflexivity. Emotion Review, 7 (1): 61-66.

Islam, G. 2015. Practitioners as theorists: para-ethnography and the collaborative study if contemporary organizations. Organizational Research Methods. 18(2): 231-254.

Jarrett, M. \& Liu. F. 2018. “Zooming With” A Participatory Approach to the Use of Video Ethnography in Organizational Studies. Organizational Research Methods, 21(2): 366-385.

Johnson, P. \& Duberley, J. 2003. Reflexivity in management research. Journal of Management Studies, 40(5): 1279-1303. 
Johnson, P., Buehring, A., Cassell, C., \& Symon, G. 2006. Evaluating qualitative management research: Towards a contingent criteriology. International Journal of Management Reviews, 8(3): 131-156.

Jonsen, K., Fendt, J. and Point, S.2018. Convincing Qualitative Research: What Constitutes Persuasive Writing? Organizational Research Methods, 21(1): 30-67.

King, N. and Brookes, J. 2016. Template analysis for business and management students. London: Sage.

Langley, A. and Stensaker, I. 2012. Longitudinal research and analysis. In C.M. Cassell and G. Symon Qualitative methods in organizational research: core methods and current challenges. London: Sage.

Miller, T., \& Boulton, M. 2007. Changing constructions of informed consent: Qualitative research and complex social worlds. Social Science \& Medicine, 65(11), 2199-2211.

Miller, J. and Glassner, B. 1997. The 'Inside' and the 'Outside': Finding Realities in Interviews In D. Silverman (Ed.) Qualitative research. $3^{\text {rd }}$ edition. London: Sage.

Myers, K. C. 2010. Reflexive Practice: Professional Thinking for a Turbulent World. New York: Palgrave Macmillan.

Özbiglin, M.F., Beauregard, A., Tatli, A \& Bell, M.P. 2011. Work-life, diversity and intersectionality: a critical review and research agenda. International Journal of Management Reviews, 13, 177-198.

Radcliffe, L.S. 2013. Qualitative diaries: uncovering the complexities of work-life decisionmaking. Qualitative research in organizations and management: an international journal. 8(2): 163-180. 
Ray, J.L. \& Smith, A.D. 2012. Using photographs to research organizations: evidence, considerations, and application in a field study. Organizational Research Methods, 15(2): 288-315.

Rees, A. and Nicholson, N. 2004. The twenty statements test. In C.M. Cassell and G. Symon, Essential guide to qualitative methods in organizational research. London: Sage.

Riach, K. 2009. Exploring Participant-centred Reflexivity in the Research Interview Sociology, 43(2): 356-370.

Ripamonti, S., Galuppo, L., Gorli, M., Scaratti, G. \& Cunliffe, A. L. 2016. Pushing action research towards reflexive practice. Journal of Management Inquiry. 25:55-68

Roulet, T.J., Gill, M.J., Stenger, S and Gill, D.J. 2017. Reconsidering the Value of Covert Research: The Role of Ambiguous Consent in Participant Observation. Organizational Research Methods 20(3): 487-517.

Ruebottom, T. and Auster, E.R. 2018. Reflexive dis/embedding: personal narrative, empowerment and the emotional dynamics of interstitial events. Organization Studies, 39(4): 467-490.

Sanghera, B. 2017. Charitable giving and reflexive individuals: How personal reflexivity mediates between structure and agency. Social Science Information, 56 (1): 28-48.

Schippers, M.C.,den Hartog, D.N., Koopman, P.L. \& van Krippenberg,D. 2008. The role of transformational leadership in enhancing team reflexivity. Human Relations, 61 (11): 1593-1616. 
Shotter, J. 1993. Conversational realities: constructing life through language. Beverley Hills: Sage.

Stiles, D. 2004. Pictorial analysis. In C.M. Cassell and G. Symon (Eds.) Essential guide to qualitative methods in organizational research. London: Sage.

Takhar, A. \& Chitakunye, P. 2012. Rich descriptions: Evoking informant self-reflexivity in marketing and consumer research. Journal of Marketing Management 28(7-8):912-35

Tams, S. and Marshall, J. 2011. Responsible careers: Systemic reflexivity in shifting landscapes. Human Relations, 64(1): 109-131.

Toraldo M. L., Islam G., Mangia G. 2016. Modes of Knowing: Video Research and the Problem of Elusive Knowledges. Organizational Research Methods Published online before print July 14, 2016, doi: 10.1177/1094428116657394

Vince, R. \& Warren, S. 2012. Participatory visual methods. In G. Symon and C.M. Cassell (Eds.) Qualitative Organizational Research: core methods and current challenges. London: Sage.

Weick, K. 2002. Essai: Real-Time Reflexivity: Prods to Reflection. Organization Studies, 23(6): 893-898.

Whiteman, G., Müller, T., Johnson, J. 2009. Strong emotions at work. Qualitative Research in Organizations and Management: An International Journal, 4(1): 46-61.

Whiting, R., Symon, G., Roby, H. \& Chamakiotis, P. 2018. What's behind the lens? A reflexive analysis of roles in participatory video analysis. Organizational Research Methods. 21(2): 316-340.

Yamauchi, Y. \& Hiramoto, H. 2016. Reflexivity of Routines: An Ethnomethodological Investigation of Initial Service Encounters at Sushi Bars in Tokyo. Organization Studies, 37 (10): 1473-1499. 
$\underline{\text { Table One: Study participants }}$

\begin{tabular}{|c|c|c|c|c|c|}
\hline Pseudonym & Sex & Age & $\underline{\text { Status }}$ & $\begin{array}{l}\text { No. of } \\
\text { Children }\end{array}$ & Occupation \\
\hline Jane & $\mathrm{F}$ & 31 & Married & 2 & Personal trainer \\
\hline Micha & $\mathrm{F}$ & 30 & Cohabiting & None & Paralegal \\
\hline Sally & $\mathrm{F}$ & 29 & Married & 1 & Primary school teacher \\
\hline Carly & $\mathrm{F}$ & 30 & Cohabiting & None & Advertising/ Media consultant \\
\hline Naomi & $\mathrm{F}$ & 31 & Single & None & School events co-ordinator \\
\hline George & M & 54 & Single & 2 & Sales assistant/ business student \\
\hline Melanie & $\mathrm{F}$ & 31 & Married & None & Senior HR advisor for a charity \\
\hline Julie & $\mathrm{F}$ & 30 & Single & None & Investment assistant \\
\hline Chloe & $\mathrm{F}$ & 32 & Single & None & Copy writer \\
\hline Louise & $\mathrm{F}$ & 32 & Cohabiting & None & Educational Psychologist \\
\hline Bill & M & 29 & Cohabiting & None & Primary School Teacher \\
\hline Belinda & $\mathrm{F}$ & 44 & Single & 2 & Shopping centre finance assistant \\
\hline Hilary & $\mathrm{F}$ & & Married & 1 & Project manager \\
\hline Ros & $\mathrm{F}$ & 52 & Married & 3 & University Teacher \\
\hline Jean & $\mathrm{F}$ & 56 & Cohabiting & None & Arts consultant \\
\hline Paul & M & & Married & 2 & University Professor \\
\hline Janette & $\mathrm{F}$ & 54 & Married & 2 & Clinical psychologist \\
\hline Sean & M & 43 & Divorced & 2 & Optimisation manager \\
\hline Catherine & $\mathrm{F}$ & 55 & Married & 2 & University Professor \\
\hline Ann & $\mathrm{F}$ & & Partnered & None & Accountant \\
\hline Roisin & $\mathrm{F}$ & & Married & 2 & Senior manager at a utility company \\
\hline Anthea & $\mathrm{F}$ & & Married & 2 & Bank manager \\
\hline Johnny & $\mathrm{M}$ & & Married & None & Manager at a waste disposal firm \\
\hline Sophie & $\mathrm{F}$ & 32 & Partnered & None & University programme coordinator \\
\hline Nazia & $\mathrm{F}$ & 20 & Single & None & University administrator \\
\hline Sandra & $\mathrm{F}$ & 56 & Cohabiting & 2 & Lecturer \\
\hline Hilary & $\mathrm{F}$ & 38 & Single & 1 & Administrator \\
\hline Jack & M & 38 & Married & 1 & lecturer \\
\hline Roxanne & $\mathrm{F}$ & 33 & Married & 2 & Lecturer \\
\hline Imogen & $\mathrm{F}$ & 44 & Married & 2 & Work-based learning coordinator \\
\hline Pamela & $\mathrm{F}$ & 45 & Single & None & Group administrator at University \\
\hline Samantha & $\mathrm{F}$ & 27 & Single & None & Administrator \\
\hline Alexi & $\mathrm{F}$ & 59 & Married & 1 & University senior manager \\
\hline Karen & $\mathrm{F}$ & 55 & Single & 3 & Lecturer \\
\hline Rosalind & $\mathrm{F}$ & 46 & Married & 2 & Recruitment consultant - self-employed \\
\hline David & $\mathrm{M}$ & 46 & Married & 1 & Student engagement officer \\
\hline Diane & $\mathrm{F}$ & 33 & Married & 1 & Student engagement manager \\
\hline
\end{tabular}


Table Two: Types of reflexive dialogue and example excerpts

\begin{tabular}{|c|c|}
\hline Reflexive dialogue & Example excerpts \\
\hline $\begin{array}{l}\text { Constructing a self-narrative } \\
\text { (including highlighting an } \\
\text { ideal - or the lack of an ideal } \\
\text { - self-narrative) }\end{array}$ & $\begin{array}{l}\text { "I was actually doing the things and then suddenly it occurred to me that it is part of the work life balance. I knew that I'd have a story to tell } \\
\text { you about how it fits to my work life balance and then I thought of sharing that with you". (Roxanne) } \\
\text { "I felt that I had to document my work space but it didn't feel it really said anything. But I felt it should be in there, so yes, I was selective. I } \\
\text { was trying to think of what these photographs said. Even if I don't think they really said anything I felt that they had to be included because I } \\
\text { couldn't think of any other way to document it". (Ann) } \\
\text { "It was quite difficult to capture different sort of themes, because I felt like the same themes kept re-occurring, the messy house, being } \\
\text { restricted, having to leave late from work. I felt those themes were just re-occurring. So trying to capture something different outside of that } \\
\text { was quite difficult ... I'd wanted to give you something a little bit more interesting but it just wasn't there". (Micha) }\end{array}$ \\
\hline $\begin{array}{l}\text { Challenging taken-for- } \\
\text { granted assumptions }\end{array}$ & $\begin{array}{l}\text { "It made me start to think a bit more actively about work-life-balance and notice where things were creeping in or taking things home, how } \\
\text { often it was, because often I found I was taking things home and I thought later "oh I could have taken a picture of that". (Naomi) } \\
\text { "There was some awareness [previously] but in talking about them [the photographs] there were things that I thought "oh, I hadn't really } \\
\text { thought about that before... In talking about it, yeah, there were a couple of times when I thought about things perhaps a bit differently from } \\
\text { how I normally would". (Sandra) } \\
\text { "It made me think I do actually have a really good deal I mean, talking about the good things in your life, and I don't know, sort of almost } \\
\text { seeing it on a piece of paper what you've got. And I know I've said it loads and loads of times throughout the interview, I'm sure, that I'm very } \\
\text { lucky". (Pamela) }\end{array}$ \\
\hline Emotional dialogue & $\begin{array}{l}\text { "Taking it made me think about it. I've worked for } 40 \text { years now and I think I know myself quite well so I know what I'm like, and I know I'm } \\
\text { very good at going "Oh I won't worry about that". Whereas I think, knowing we were having the conversation, thinking about this, did make } \\
\text { me think of ..yeah... the whole process, and it's again because of certain things that are going on here [at work] at the moment anyway and } \\
\text { making me re-evaluate my work/life balance in the sense of I don't think I'm being rewarded for what I'm doing, therefore I am now thinking } \\
\text { to myself "Well, why am I carrying on doing it? Have I got 'mug' tattooed across me...?" (Alexi) } \\
\\
\text { "I think we talked a little bit just now about how I feel I'm failing at work a little bit, I think in some ways I'm sort of failing as a father } \\
\text { because I can see that I'm still very work-orientated. If we should be } 50-50 \text { work, and I know it's not as simple as that, but if we should be, I } \\
\text { think I'm } 80 / 20 \text { or something. I'm not right, I'm definitely too work - so I feel guilty as far as the amount of time I'm able to devote to my } \\
\text { child and my wife... But there is some joy as well, because there's [my son] on the desktop there, which is clearly a photograph, it's }\end{array}$ \\
\hline
\end{tabular}




\begin{tabular}{|c|c|}
\hline & $\begin{array}{l}\text { something I want to look at... just looking at it makes me feel stressed, at the same time, looking at it makes me feel, you know, kind of like } \\
\text { oh, bless him... There's all of that emotion too". (David) } \\
\text { "Some of them provoked emotion. It did make you think about it when you put it together like that, a series of } 6 \text { or } 7 \text { photographs trying to } \\
\text { reflect your work life balance". (Imogen) }\end{array}$ \\
\hline Action dialogue & $\begin{array}{l}\text { "It has made you reflect on it more, because I think often everything is happening so fast and you're noticing it but you're not thinking about } \\
\text { it. So, it's made me actually think actually why aren't I approaching, why haven't I pushed to have meetings with my boss? You just think } \\
\text { maybe I shouldn't, I don't know, and then you think actually, it's probably not a big deal to just say can we meet every week. It makes you } \\
\text { think more about it and then look for solutions or be more proactive about making things happen.” (Naomi) } \\
\text { "It helped me have a conversation with my husband! He was quite intrigued by it all, actually, and we do have conversations about work/life } \\
\text { balance and how much you share between us as a couple, and it was an introduction to that conversation, which we haven't had for a while. So, } \\
\text { it was useful in that sense, and it was quite an interesting conversation incidentally, because he does work away and he's not overly happy } \\
\text { working away ... So, it's prompted him; he's looking at jobs at the moment”.(Roisin) } \\
\text { " [It made me feel] quite funny in a way, because looking at the photographs now, especially the bags under my desk and the messy dressing } \\
\text { table, it just makes me think ... it's quite funny because I just know that it's not going to be resolved anytime soon. So I'd rather laugh about it, } \\
\text { in a way. It just makes me feel ... yeah, it's just so typical... it's made me realise how typical my life has become in terms of trying to manage } \\
\text { everything, and it's been going on for so long so it's just sort of brought it back to me how typical it is and how long this has been going on } \\
\text { for. It just makes me feel a bit apprehensive about the future in terms of whether anything is going to change at any time or if it's just going to } \\
\text { get worse, if it's ever going to get better. Probably not. It's a bit cynical”. (Micha) }\end{array}$ \\
\hline
\end{tabular}


Table Three: Facilitating and accessing participant reflexivity methodologically

\begin{tabular}{|c|c|c|}
\hline $\begin{array}{c}\text { Characteristic of research } \\
\text { design }\end{array}$ & Methodological facilitators & Example excerpt \\
\hline $\begin{array}{l}\text { An opportunity for reflexive } \\
\text { space - facilitates reflexivity }\end{array}$ & $\begin{array}{l}\text { A longitudinal element. Allocation of a period of } \\
\text { time (a "window of opportunity") between the } \\
\text { participant completing the activity and the discussion } \\
\text { of their data with the researcher permitting additional } \\
\text { time for reflection. Time is required for participants } \\
\text { to have their own internal conversations (Archer, } \\
\text { 2007). }\end{array}$ & $\begin{array}{l}\text { "Because you're so busy just doing it, just busy in the moment of getting through } \\
\text { each day and doing everything that you need to do. You don't sit back and reflect on } \\
\text { it because you don't have the time. (Sally) } \\
\text { "I think I was trying to find the time to do it and I kept forgetting. But I think it's a } \\
\text { great idea and I think it's not just taking the photograph, for me it was looking } \\
\text { through photographs that I had taken and then reflecting on them and thinking } \\
\text { actually, this is something that means a lot". (Hilary) } \\
\text { "Remembering [to take the photographs] was the main thing, because sometimes } \\
\text { the moment's gone. But then I think what I've realised is that a lot of the conflicts } \\
\text { are the same ones, they just recur. So even though you've missed that chance it did } \\
\text { happen again so it wasn't like it was lost forever". (Naomi) }\end{array}$ \\
\hline $\begin{array}{l}\text { Participant's anticipation of the } \\
\text { requirement to share with the } \\
\text { researcher - facilitates } \\
\text { reflexivity }\end{array}$ & $\begin{array}{l}\text { Some activity by the participant without the } \\
\text { researcher present that is required for research } \\
\text { participation, the output of which will be shared with } \\
\text { the researcher. Examples include taking a } \\
\text { photograph; completing a diary; filling in a } \\
\text { questionnaire; doing a Twenty Statements Test; } \\
\text { seeing a copy of the interview questions before the } \\
\text { interview takes place. }\end{array}$ & $\begin{array}{l}\text { "I'm thinking that's really good because that will stimulate a conversation around } \\
\text { this. I took the picture of the coffee cup because I thought I want to stimulate a } \\
\text { conversation around that, that's important to me". (Paul) } \\
\text { "I found it really interesting. I started off being really literal. There are photographs } \\
\text { when I got in late from work, Marks and Spencer's bag with ready meal but I cook } \\
\text { it with a clock, a strategically placed clock and stuff like that, and then I just kind of } \\
\text { relaxed more into well, what is work and what is life? So it made me think about } \\
\text { what I was doing as well. So I thought it was an interesting way of gathering things. } \\
\text { But it's interesting just going through them with you. I kind of think, "oh why did I } \\
\text { send **** that picture?" But there's generally something to say about it". (Jean). } \\
\text { "I didn't take that many but I was selective in the sense that I thought about what I } \\
\text { was going to take and I thought this would be a good one. I guess my criteria was } \\
\text { what would I try and show from this photograph. So I tried to think about what } \\
\text { would that actually, what information would that give".(Melanie) }\end{array}$ \\
\hline
\end{tabular}




\begin{tabular}{|c|c|c|}
\hline $\begin{array}{l}\text { Participant Control - facilitates } \\
\text { reflexivity }\end{array}$ & $\begin{array}{l}\text { Participant control over the data provided, for } \\
\text { example when the initial stage of data collection } \\
\text { takes place without the researcher and the participant } \\
\text { decides what data they will offer to the researcher } \\
\text { rather than offering data in situ (for example via a } \\
\text { face-to-face interview). Requires a participant-led } \\
\text { data collection method where they have to think } \\
\text { about what they will focus on, for example taking a } \\
\text { photograph, making a video, filling in a diary. } \\
\text { Perception of safety and the provision of a } \\
\text { comfortable environment for reflexivity. }\end{array}$ & $\begin{array}{l}\text { "It was a way of being able to, a sort of non-threatening way of being able to } \\
\text { disclose what you want to and as much as you want to about the context". (Sandra) } \\
\text { "It was good, I think it breaks down the barrier, because you're [the researcher] not } \\
\text { going to know some of these people, they're going to be ... it is quite personal and it } \\
\text { makes you much more comfortable as you then move into the questions". (Hilary) } \\
\text { "I enjoyed doing it because it told me something that I kind of... if you had sat me } \\
\text { down and said "what's your work/life balance like?" I would have said rubbish } \\
\text { anyway, but it told me in a much more personal way than if you had just asked me } \\
\text { questions". (Anthea) }\end{array}$ \\
\hline $\begin{array}{l}\text { Relational dialogue }- \text { enables } \\
\text { access to reflexive thinking }\end{array}$ & $\begin{array}{l}\text { Less structured, more open, narrative style interviews } \\
\text { that permit participants some control, opportunity } \\
\text { and space to share their personal stories and } \\
\text { perspectives. Listening actively and summarizing } \\
\text { back key parts of participants' stories. } \\
\text { Asking explicit questions about internal } \\
\text { conversations, self-narratives and self-presentation } \\
\text { (e.g. 'how did you decide what photographs to share } \\
\text { with us?') } \\
\text { Emotional awareness - paying attention to participant } \\
\text { emotions, being aware of links between emotions and } \\
\text { participant reflexivity and exploring emotions and } \\
\text { their impact on reflexivity further where appropriate. }\end{array}$ & $\begin{array}{l}\text { "When I first saw the sheet saying what to do I thought "that's all right but I don't } \\
\text { know how to take photographs. What am I supposed to take photographs of to } \\
\text { illustrate my work life balance? What does that mean?" But when it came to it, } \\
\text { yeah, I could do it. I think it was quite meaningful, just as a way of being able to } \\
\text { start a conversation, to have something to focus on to start the conversation". (Jean) } \\
\text { "I loved talking about the photographs. I loved doing that". (Roxanne) }\end{array}$ \\
\hline
\end{tabular}


Table four: The added value of accessing participant reflexivity

\begin{tabular}{|c|c|c|}
\hline Advantage of using PR & Example from the study & Data excerpt \\
\hline $\begin{array}{l}\text { Promotes and positions } \\
\text { research participants as } \\
\text { reflexive individuals }\end{array}$ & $\begin{array}{l}\text { Enables access to the participant } \\
\text { reflexivity that the research process is } \\
\text { likely to instigate: the reflexive thinking } \\
\text { that arises from everyday internal } \\
\text { conversations (Archer, 2017) }\end{array}$ & $\begin{array}{l}\text { "I suppose it's strange to talk about some things out loud that you don't really always talk about on a } \\
\text { regular basis. They're probably things that you always think about but you don't necessarily talk } \\
\text { about out loud. It's interesting to see your own point of view on your work life balance. It's } \\
\text { probably something I never would reflect on otherwise". (Sally) } \\
\text { "It brought my awareness to the issue of work life balance more than otherwise it would come into } \\
\text { my mind. It does come in occasionally but during the period while I was taking photographs I was } \\
\text { sort of slightly more aware of it because I was looking for opportunities or something ... if I was in a } \\
\text { situation where I had the thought, "oh I wish I could do that," either work or home, then I would } \\
\text { think to take a photograph". (Sandra) } \\
\text { "It was really useful, because it's there in the back of your head, it kind of made you think actually, } \\
\text { and talking about it even more so, because it does make it ... it feels a bit like self-therapy and you } \\
\text { think actually ...it's a big pat on the pack for yourself in a way because it makes you think actually, I } \\
\text { manage things quite well. I think I feel in control, and there have been times in my life when I } \\
\text { haven't been in control at all and it felt very messy". (Imogen) }\end{array}$ \\
\hline $\begin{array}{l}\text { Access to individual } \\
\text { sensemaking enables a } \\
\text { more nuanced and in-depth } \\
\text { interpretation of our data }\end{array}$ & $\begin{array}{l}\text { In depth analysis from participants about } \\
\text { their rationale for why they do particular } \\
\text { things or why particular things are } \\
\text { important to them, enabling the access to } \\
\text { personal sensemaking. Rather than data } \\
\text { generated in situ, the participant has } \\
\text { already started the analysis process. }\end{array}$ & $\begin{array}{l}\text { "Because on the calendar I circle dates that I've got planned and dates that I'm looking forward to } \\
\text { for something and I like to have it in front ... I've got my diary as well, but I like to have just that } \\
\text { calendar on my desk... it's just to sort of break the working day up... it's like a strategy and I guess } \\
\text { a distraction as well. I think, because it's quite ... my work is really stressful, and I feel it I like to } \\
\text { have a distraction at work and I use my own personal life to break away from it, I think." } \\
\\
\text { I think it's just ... I guess the thing about taking the picture of the lunch, actually I guess again it was } \\
\text { like I can feel sorry for myself because I always have lunch at my desk but even just talking about } \\
\text { it, I don't have to do that. That's my decision. So that again makes you realise that these things are } \\
\text { actually in your own control mostly. Well, they are in my situation. Yeah, I guess that again is a } \\
\text { good thing, so definitely I've got a lot of flexibility where I work". (Melanie) }\end{array}$ \\
\hline $\begin{array}{l}\text { More nuanced } \\
\text { understanding of our } \\
\text { research topic }\end{array}$ & $\begin{array}{l}\text { Access to individual's internal } \\
\text { discussions about how they understand } \\
\text { the concept of work-life balance. Access }\end{array}$ & $\begin{array}{l}\text { "When you say work life balance you immediately think of the downsides of working and having a } \\
\text { family life at the same time. That's probably the first thing that springs to mind when you say that, is } \\
\text { oh I come up with a list of the difficult things rather than the positive". (Sally). }\end{array}$ \\
\hline
\end{tabular}




\begin{tabular}{|c|c|c|}
\hline & $\begin{array}{l}\text { to an understanding of the normative } \\
\text { pressures individuals face in terms of } \\
\text { seeking the elusive, perfect work-life } \\
\text { balance. }\end{array}$ & $\begin{array}{l}\text { "I had to think about what I was going to take a picture of and I had to think about what are the key } \\
\text { kind of features in my work life balance, kids, the office, my calendar, the gym". (Imogen). } \\
\text { "I was thinking about work-life balance and I was thinking about what I do and it just came to me. } \\
\text { What I didn't have [in the phgotographs], which is the downside, is that there wasn't the walk in the } \\
\text { park, which I would have loved there to have been..." (Anthea). }\end{array}$ \\
\hline $\begin{array}{l}\text { Surfacing of emotions and } \\
\text { exploring the link between } \\
\text { emotions, reflexivity and } \\
\text { action }\end{array}$ & $\begin{array}{l}\text { Access to both positive and negative } \\
\text { emotions associated with work-life } \\
\text { balance and seeing how reflexivity can } \\
\text { be a call to action in some contexts. }\end{array}$ & $\begin{array}{l}\text { "Making me re-evaluate my work/life balance in the sense of I don't think I'm being rewarded for } \\
\text { what I'm doing, therefore I am now thinking to myself "Well, why am I carrying on doing it? Have I } \\
\text { got 'mug' tattooed across me...?" (Alexi) } \\
\text { "The difficult things are harder to deal with on a daily basis than the positive things. The positive } \\
\text { things are great and they maybe pass you by and the negative things are the things that you have to } \\
\text { spend more time trying to resolve and trying to work your way round". (Sally) } \\
\text { "It's quite an emotional thing, isn't it? I think if I sat there and went through all } 20 \ldots \text { when I was } \\
\text { putting the photographs on here earlier I was thinking it's quite emotive and it really makes you } \\
\text { think and then it could be quite upsetting, you know, when you talk about I want more time with my } \\
\text { daughter, or it makes it go round in your head so it's a bit of an emotional thing to talk through". } \\
\text { (Hilary) }\end{array}$ \\
\hline $\begin{array}{l}\text { Enabling the researcher's } \\
\text { own reflexive processes }\end{array}$ & $\begin{array}{l}\text { Interaction between the reflexive } \\
\text { analysis of the research data by both the } \\
\text { researcher and the researched. }\end{array}$ & \\
\hline
\end{tabular}

